\title{
Strategic Planning: A Remedy for the Successful Management of Nigeria Secondary School System
}

\section{Sokpuwu Ikubor Austin}

Department of Educational Management, Ignatius Ajuru University of Education, Port Harcourt, Nigeria

\section{Email address:}

aust_royal@yahoo.co.uk

\section{To cite this article:}

Sokpuwu Ikubor Austin. Strategic Planning: A Remedy for the Successful Management of Nigeria Secondary School System. International Journal of Secondary Education. Vol. 8, No. 2, 2020, pp. 53-68. doi: 10.11648/j.ijsedu.20200802.15

Received: January 13, 2020; Accepted: June 3, 2020; Published: June 17, 2020

\begin{abstract}
This paper examined the need for strategic planning as a remedy for successful management of secondary school systems in Nigeria. The research design used was a descriptive review, which reveals the strong connection between strategic planning and successful management of the secondary school system in Nigeria. The Nigerian secondary school system has encountered quite a number of challenges Inadequate infrastructure, instructional materials and Facilities School, Inadequate motivation/Staff Low Morale Teachers, Poor education board and Ministry Monitoring/Supervision of Schools, Poor Funding, Unqualified and inadequate teachers, Poor Application of ICT Computer learning and Non-involvement of stakeholders/Teachers in key Decision-making and Planning amongst others. This paper looks at the meaning and context of strategic planning its process, approaches, elements and use in education. SWOT analysis approach was examined with model sample. The paper concludes that despite the several issues plaguing the Nigerian secondary school system, with the proper adoption and implementation of strategic planning and management, the expectations of the national policy on education on secondary school can still be achieved for the benefit of both the school and nation.
\end{abstract}

Keywords: Strategic Planning, Secondary School, Strategic Management, SWOT Analysis

\section{Introduction}

There is a big challenge for improving secondary education in order to achieve the goals defined in the National Policy on Education [20]. If Nigeria is to realize her vision of becoming one of the largest twenty economies in the world by the year 2020, (although this appears not feasible) then there is a great need to transform her largely dependent population into highly skilled and competent citizens capable of competing globally. There have been a lot of hue and cry about the decadent state of Nigerian secondary school system. This is also attested to by recent poor performance in both internal and external examinations like WAEC exams and JAMB-CBT examination; they lack adequate skills and vocational knowledge, and not well cultured. The decadent state of secondary school educational sector in Nigeria which is supposed to be a breeding ground for higher institutions has been of significant concern and issue of discussion among critical stakeholders and the society. More worrisome are the products of these secondary schools especially the public secondary schools. Most of these products are lack the basic capacity to fit into the $21^{\text {st }}$ century challenges.

It is worthy to state here that the Nigeria national policy on education [20] has lofty aims and objectives for our secondary school system:

\subsection{Aims of Secondary Education in Nigeria}

The Federal Government of Nigeria has clearly spelt the aims and objectives of secondary education in the country to include preparation for:

(a) Useful living within the society; and

(b) Higher education

In Specific Terms Secondary Education Shall

(a) Provide all primary school leavers with the opportunity for education of a higher level, irrespective of sex, social status, religious or ethnic background.

(b) Offer diversified curriculum to cater for the differences in talents, opportunities and future roles,

(c) Provide trained manpower in applied science, technology and commerce at sub professional grades,

(d) Develop and promote Nigerian languages, art and 
culture in the context of world's cultural heritage,

(e) Inspire students with a desire for self-improvement and achievement of excellence,

(f) Foster national unity with an emphasis on the common ties that unite us in our diversity,

(g) Raise a generation of people who can think for themselves, respect the views and feeling of others, respect the dignity of labour, appreciate those values specified under our broad national goals and live as good citizens;

(h) Provide technical knowledge and vocational skills necessary for agricultural, industrial, commercial and economic development.

(I) Equip students to live effectively in our modern age of science and technology [20].

From the objectives outlined, we can deduce that the secondary school education sector is consequently pivotal to the actualization of the current national and global policy objectives. Secondary education in Nigeria is one of the levels of education for the achievement of the philosophy and objectives of Nigerian Education as highlighted in the National Policy in Education [21].

This, policy when well implemented through strategic planning and management will foster the much needed peace, unity and development in Nigeria. The policy is not only confident that education is the greatest force that can bring about positive improvement in these areas but also, the greatest investment that the nation can make for quick development of its abundant (economic, political, sociological and human) resources. Presently these objectives are far from being achieved. The perceived achievements made cannot even be effectively measured, hence there is great and urgent need for strategic planning in the successful management of secondary school system.

Presently secondary schools in Nigeria are characterized by inadequacy of infrastructure, inadequate instructional facilities, shortage of qualified subject area personnel, declining standard, prevalent of cultism, examination malpractices, poor involvement of teachers in decision making and curriculum planning, poor motivation of staffs, low use of information and communication technology and maladministration. From the foregoing there appears to be a persistent and wide-spread loss of confidence in public secondary school system. Ajayi (2011) aligned with this position when he noted, that public education today has been faced with various challenges ranging from mismanagement of allocated resources, to falling academic standards. He also added that other important reasons for loss of confidence in our educational system include poor planning and consistent lack of investment in the education system. Educational facilities at all levels are in a terrible shape; schools are littered with battered structures; worn out equipment (where they are available at all); junk and unserviceable vehicles; raggedy classroom buildings; over-crowded classrooms; inadequate manpower in quantity and quality; instability in the academic calendar owing to strikes; very low teacher (staff) morale due to poor remuneration and working conditions [2]. This allegation has been supported by
Ajobiewe, (2008) who noted with gross dissatisfaction this lack of quality education delivery and output in Nigerian secondary school education sector today.

These aims and objectives of Nigerian secondary school system, when critically studied will show the intention of the policy on self-reliant tendency of the individual for selfimprovement and national development. So this stage of secondary education system require sustained development so that it can effectively possess the ability to train the citizens. There is the need to make education more functional, qualitative as well as quantitative so that more people could have access to it.

The classification of Nigeria's secondary education into two segments of (the Junior Secondary Education, and the Senior Secondary Education, with a duration of 3 years each) makes strategic planning and management an important tool in the implementation of a diversified curriculum for the attainment of short-term, medium-term and long-term goals.

Every institutional management needs a tool that has the potential to improve the successful management of educational institutions; that tool is strategic planning. Strategic planning is important to any organizational work performance because it determines the organization's success or failure.

Ololube, \& Kpolovie, (2013) had defined educational planning as: The application of rational, systematic analysis to the process of educational development with the aim of making education more effective and efficient in responding to the needs and goals of its students and society.[46] This is same with the key concepts of strategic planning.

Such a strategy according to Bryson, (2011) is actually a plan that is intended to achieve a particular purpose. It is a disciplined effort to produce fundamental decisions and actions that shape and guide what an organization is, what it does and how it does it with a focus on the future. Chukwumah (2015) in his work stated that there is an increasing need for effective and efficient development of strategic plan for secondary schools [15]. Introducing strategies and plans to Nigerian secondary school system of education will improve the standard and bring the schools to effective self-management.

A school's strategic plan is the physical document that embodies the guiding orientation regarding how to manage the school within a larger national and local development policy/perspective. Such a plan can lead to school effectiveness, improvement and development when properly implemented.

In this paper, Strategic planning is seriously advocated for because many institutions and organizations now find themselves in circumstances where old methods of planning and management are no longer effective in dealing with both present and future challenges. It is used to provide the institutions, stakeholders and administrators with a clearer future of how a rapidly changing environment is shaping the critical decisions that their institutions face and how it is conditioning the resources that the institution is likely to have to support its decisions. 
Through the strategic planning process schools could focus more sharply in their choice of goals, objectives and strategies for accomplishing those goals, helping to move the institution in an appropriate direction [16]. Apart from this, a key aspect of strategic planning for schools is the opportunity afforded for grass-roots level engagement of stakeholders through consultation and participation in the planning process.

As stated by Chang, (2008) a strategic plan is a living document that includes policy direction, implementation strategies, actions and benchmarks for implementation, monitoring and evaluation, as well as the expenditure framework which allows adjustments in areas for developments during implementation [13]. This plan entails the school's analysis of its strategic issues for development, prioritization, planning to address such issues and, finally, implementing a plan to address these identified issues for development. It ensures that the learners receive quality education in terms of total development and academic achievement. This School Developed Strategic Plan is an active document which reflects a complete self-evaluation reports of the school and its objectives. It is on this ground that some governments-Anambra state-Nigeria (ICMBA, 2004) and Kenya (Okenwa, 2013) had made it mandatory for institutions to develop strategic plans in line with its national educational strategic policy. Such plans offers direction in regard to resource routing and programmes implementation.

Chukwumah, (2015) Stated that the Nigeria Education systems must have a powerful and coherent educational improvement strategy in order to improve student academic achievement [15]. The sole aim of this Strategic Plan is to provide leadership and direction to all those within the secondary school education sector in Nigeria by setting out a clear and agreed agenda for action.

Although The Federal Government of Nigeria [20] in her National Policy on Education had instructed all educational institutions to get involved in developing strategic plans in order to promote education provision and service delivery. Many institutions are yet to comply with this directive, hence this paper is met to broaden our understanding of the theme for proper implementation as a remedy for successful management of our secondary school system.

\subsection{Statement of the Problem}

There are no available data from internet search that shows that secondary schools in Nigeria has operating strategic plan At their individual school levels. Strategic planning is key to school success. Poor planning leads to poor performance, it is like having no plan to win at all. It is expected that the school should meet the expectations of the stakeholders (Parents, students, staff, the host community and the nation at large). Strategic planning positions school administrators with the advantage of having insight into the future, identify trending issues and the need to reposition, rebrand, modify and restructure in order to confront new tasks and set new frontiers.

Although it is the requirement of Ministry of Education that all schools formulate strategic plans with a time frame of three years, yet some schools rarely develop strategic plans leading to poor school management hence lowering the academic standards and poor school environment. The continuous poor performance of schools at both internal and external examination is quite worrisome. This can be adduce to poor strategic management of our secondary schools. The federal Government had confirmed that most secondary school principals do not have school vision statement, student target and strategic plan document. The absence of such important elements makes the plan incomplete thus poor implementation of even the national policy on education.

This paper therefore aims at examining the conceptual issues around developing strategic plans document for proper implementation.

\subsection{Purpose of the Chapter}

Internet searches have shown that there are scanty studies on strategic Planning/analysis as a tool for effective secondary school management especially in Nigeria. This research is intended to enlarge our understanding by examining how best secondary school principals and administrators can leverage on strategic planning process as practical hands on tools: analyze their strengths, weaknesses, opportunities and threats to the advantage of their schools visa-vis to improve the management of our schools at this level.

The specific objectives of this research are to:

I. Define specific concepts used in this text such as strategic planning,

II. Examine the process, and elements of strategic planning

III. Discuss some of the issues, problems facing the Nigerian secondary school system

IV. It is also to amplify the need for strategic planning as a tool for the successful management of secondary schools,

V. Highlight how the application of the concept and process of strategic planning can offer solutions to the present management problems of our secondary school system.

VI. Make suggestions with model sample to guide its application

VII. Make suggestion to guide future research on subject matter.

However planning and the ability to think strategically by planners, managers and employees alike, feed into the strategic plan document. Although the strategic plan document is not the most valuable output of the strategic planning formation process, neither is it a definite output, it is however tangible evidence that includes most of the planning efforts. The document is expected to provide well-justified answers to the strategic questions by stakeholders and should be used as a basis for communication.

The conceptual definitions, conclusions and recommendations of this paper are expected to provide a framework or process which should assist school principals 
and management in making decisions on how to initiate, develop and implement strategic planning tool in effective schools management. The planners and policy makers are expected to use this paper as a base for generating a better approach to school management in order to overcome the challenges hindering smooth implementation of national secondary school system educational policy in schools in Nigeria. Further, findings of the study are expected to open areas for further study by other researchers and academicians, hence benefiting the whole community

\section{Literature Review}

\subsection{Clarification of Concepts}

For a more understanding of the topic under discussion, it will be necessary to give some definitions and clarifications of specific concepts used in this paper such as:

\subsection{The concept of Strategic Planning}

A strategic plan is an important management tool. It sets a clear direction for the organization, improves performance, helps resolve current challenges and avoid future problems, and provides a framework for decision-making. Strategic planning is "the process by which the guiding members of an organization envision its future and develop the necessary procedures and operations to achieve that future" [25]. Strategic planning "assumes that an organization must be responsive to an environment which is dynamic and hard to predict" [5].

Strategic planning is the process of setting goals, it is also called Goal directed planning, it means deciding on actions to achieve those goals and mobilizing the resources needed to take those actions. A strategic plan describes how goals will be achieved through the use of available resources.

Strategic planning is the process of reflecting on past performance, establishing future directions and deciding what will constitute success. In other words, it involves the school community considering these questions:

a) where have we been?

b) where do we want to go?

c) how will we get there?

d) how will we know if we have been successful?

Lawrence, (2001) noted that Strategic Planning was adopted from the army where this concept originated from after the Second World War into learning institution as a means of achieving school effectiveness. Fehnel, (2000) in his approach defined strategic planning, as a systematic process in which an organization envisions its future and assesses its basic reason for being (i.e. its purpose or mission), what are the strengths, weaknesses, opportunities and threats (SWOT) it might face in the immediate and foreseeable future [23].

\subsection{Models and Approaches to Strategic Planning}

There are many models available to assist in the strategic planning process.

\subsection{1. (A). Bryson Strategic Planning Cycle}

Bryson introduces a strategic planning steps/model that was originally developed for public and non- profit organizations. This Cycle includes ten steps to follow while planning. Schools in Manitoba-Canada had adopted this model [52]. Bryson, (2011) ten steps cycle includes:

1. Initiate and agree upon a strategic planning process.

2. Identify organizational mandates.

3. Clarify organizational mission and values.

4. Assess the organization's external and internal environments to identify strengths, weaknesses, opportunities, and threats.

5. Identify the strategic issues facing the organization.

6. Formulate strategies to manage these issues.

7. Review and adopt the strategic plan or plans.

8. Establish an effective organizational vision.

9. Develop an effective implementation process.

10. Reassess strategies and the strategic planning process.

\subsection{2. (B). Goodstein, L. D., Nolan, T. M., \& Pfeiffer, J. M..} Strategic Planning Model

Goodstein, Nolan, \& Pfeiffer (1993) Provided a model of strategic planning. The model involves nine phases that includes seven sequential steps and a step that has two components. There are also two continuous processes occurring during the nine phases.

1. Planning to Plan: In this step the organization needs to make certain "that there is organizational commitment to the process". Without this commitment strategic planning will not work.

2. Values Scan: this allows for the examination of the members of a planning team, the values of the organization, the philosophy of operations, the culture, and stakeholder values.

3. Mission Formulation: in formulating its mission, an organization must answer four primary questions:

(i). what function (s) does the institution perform? (ii). For whom does the organization perform this function? (iii). How does the organization go about filling the function? (iv). Why does this organization exist?

4. Strategic Business Modeling: This involves the initial attempt to detail the process by which the organization will accomplish its mission.

5. Performance Audit: This allows for a clear understanding of the organization's current performance after envisioning the organization's future.

6. The Gap Analysis happens after the Performance Audit has been completed and "identifies gaps between the current performance of the organization and the desired performance required for the successful realization of its strategic business model".

Step 5 and 6 occurs at the same time, but are two different aspect.

7. Integrating Action Teams: State that once the gaps are revealed two issues need to be addressed. The first is that the master business plan must be created and the second is that detailed operational plans need to be developed. 
8. Contingency Planning: Contingency Planning involves the following:

1. Identifying the most important internal and external threats to and opportunities for the organization, especially those involving other than the most-likely scenarios. 2 . Developing trigger points to initiate action steps for each contingency. 3. Agreeing on which action steps will be taken for each of these trigger points.

9. Implementation: this phase involves the initiation of action plans that have been designed at the functional level and are integrated at the top.

Also occurring simultaneously during the nine phases listed above are Environmental Monitoring and Application Considerations. They found that four environments need to be monitored during the strategic planning process: the macro environment, the industry environment, the competitive environment, and the internal environment. Application Considerations provide for continuous integration and checking of each of the nine phases.

By answering these questions a school should see improved academic performance, and an enhanced culture of learning and positive behaviors.

It's hard to accomplish anything without a plan. Whether you're coaching a football team, cooking Thanksgiving dinner, or running a small business, you need a strategic plan.

A strategic plan looks at all the things your small business could do and narrows it down to the things it is actually good at doing. A strategic plan also helps business leaders determine where to spend time, human capital, and money.

But, how should small businesses approach strategic planning? There are hundreds of business books dedicated to the topic. We've read most of them. We put the others on our bookshelf just for show.

\subsection{3. (C.) Alexa, A (2011) in Forbes Entrepreneurs Newsletter Put Forward a 5-step Approach to Strategic Planning}

1. Determine where you are. This is harder than is looks. Some people see themselves how they WANT to see themselves, not how they actually appear to others. Many small institutions get snared in this same trap.

For an accurate picture of where your business is, conduct external and internal audits to get a clear understanding of the marketplace, the competitive environment, and your organization's competencies (your real-not perceivedcompetencies).

2. Identify what's important. Focus on where you want to take your organization over time. This sets the direction of the enterprise over the long term and clearly defines the mission (markets, customers, products, etc.) and vision (conceptualization of what your organization's future should or could be).

From this analysis, you can determine the priority issuesthose issues so significant to the overall well-being of the enterprise that they require the full and immediate attention of the entire management team. The strategic plan should focus on these issues.
3. Define what you must achieve. Define the expected objectives that clearly state what your organization must achieve to address the priority issues.

4. Determine who is accountable. This is how you're going to get to where you want to go. The strategies, action plans, and budgets are all steps in the process that effectively communicates how you will allocate time, human capital, and money to address the priority issues and achieve the defined objectives.

5. Review. Review. Review. It's not over. It's never over. To ensure the plan performs as designed, you must hold regularly scheduled formal reviews of the process and refine as necessary. We suggest at least once a quarter.

A strategic plan is a wonderful thing. It can help you take your small business to places you never thought possible. If you haven't already done so, take the time to lay out a strategic plan now. It will help keep your small business on track and you focused on the future.

\subsection{4. (D). The SWOT Approach}

S. W. O. T. analysis is basically a framework for making calculated, informed decisions. Here's a quick glance at each element of S. W. O. T.

Strengths: What is your team really good at? What do you offer people that others can't or don't?

Weaknesses: What are some things that your team is not very good at, that others do much better?

Opportunities: What are some areas that your organization could thrive in that it isn't currently taking advantage of?

Threats: What are some external factors-competitors, consumer demand, economic conditions - that could make it more difficult for your team to succeed?

SWOT is a management tool to formulate strategic action plans. SWOT is an acronym for strengths, weaknesses, opportunities and threats. SWOT matrix analyzes the internal strengths and weaknesses as well as external opportunities and threats to derive promising future strategies. [48].

\subsection{Elements (Parts) of a Developed Strategic Plan}

A Typical, strategic plan includes the following elements: setting a vision for the organization; scanning the external environment; assessing internal capabilities; and establishing goals, performance measures, and implementation of plans. Strategic planning keeps the organization focused. [30]

A strategic plan components at a minimum, should generally include the following sections:

a) a vision statement (A vivid, descriptive image of the future - what the organization will BECOME)

b) a mission statement (States WHY the organization exists and WHOM it serves)

c) an outline of goals, objectives, and activities

d) an assessment of current resources, (SWOT analysis is used here) and

e) a strategic analysis. 


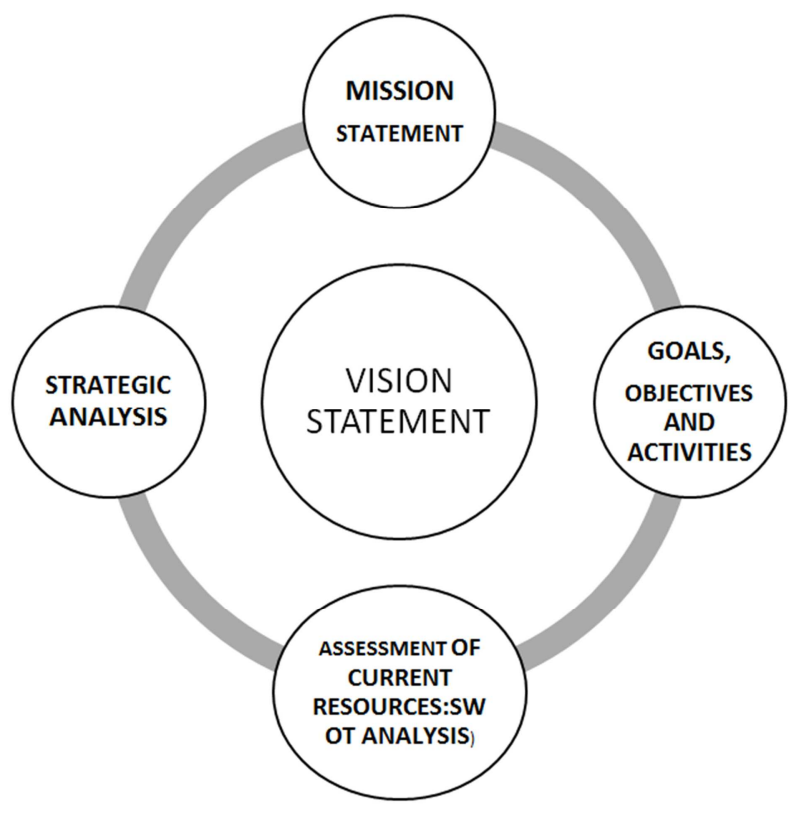

Figure 1. A MODEL OF THE BASIC ELEMENTS OF A STAREGIC PLAN.

Other strategic plan components includes time-frame, targets, output, outcome and indicators of performance. These components forms the benchmark of assessment of any successful school management.

It is from these actions steps that the strategic plan document is produced. The importance of a strategic plan document cannot be over-emphasized as a document used to communicate with the organization, the organizations goals, the actions needed to achieve those goals and all of the other critical elements developed during the planning exercise.

Such strategic plans usually has pragmatic objectives, guidelines, specific goals and targets and a timeline for completion. The Targets are simply expressed without vagueness, which makes evaluation easy. This means that the institutions aiming at improving their situation needs to get involved in practical strategic planning. A well-developed strategic plan facilitates proper implementation.

\subsection{Stages in Strategic Planning}

Olaniyonu, Adekoya, \& Gbenu, (2008) weighing in on SWOT analysis approach opined that there are four stages every strategic planning process should pass through namely: Strategic analysis, strategic formulation, strategic implementation and strategic control/evaluation [42].

1. Strategic Analysis according to Ololube, Agbor, \& Kpolovie, (2016) is the principal stage of the strategic planning process, which is aimed at evaluating the present condition of the school. That is, it requires a detailed assessment of the school's internal and external environment. He added that The purpose of strategic analysis in the school planning process is to identify the school's assets, skills, and resources that represent strengths, weaknesses, opportunities and threats (SWOT). Strengths are favourable internal features that the school can apply to accomplish its strategic aims. Weaknesses are internal facets that hinder or limit goal accomplishment. Opportunities are features of the external environment that will cause the school to realize its aims and objectives if it cannot resist or avoid them. Threats are features of the external environment that might favour the university provided it is able to take advantage of them [47]. Strategic analysis examines the present position of the school.

Table 1. A model SWOT Analysis Result.

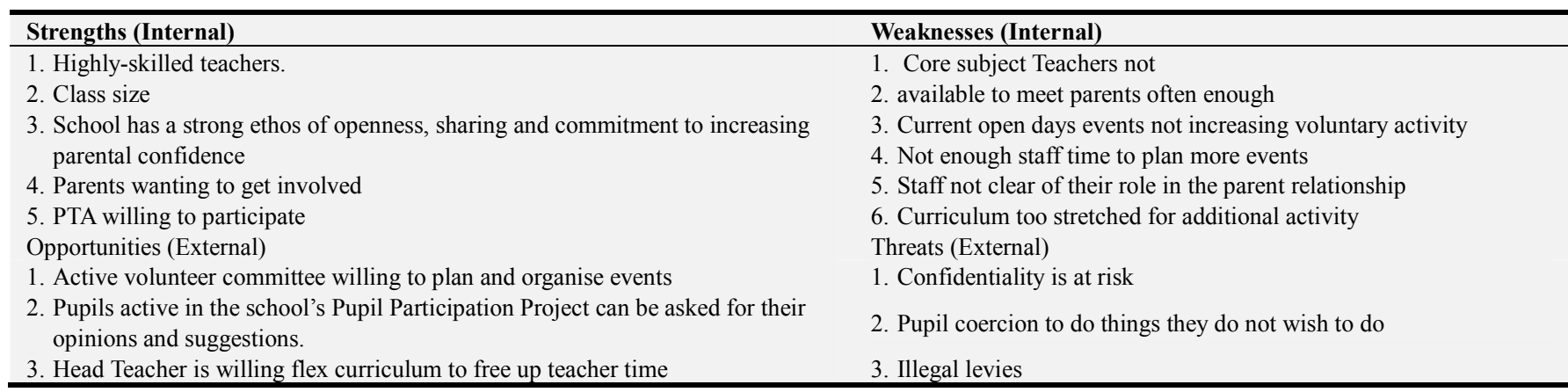

SWOT is a management tool to formulate strategic action plans. SWOT is an acronym for strengths, weaknesses, opportunities and threats. "SWOT" analysis: Assess the organization's: - Internal Strengths - Internal Weaknesses External Opportunities - and External Threats. There are a minimum of four step to follow when using SWOT analysis:

Step 1 of SWOT analysis involves the collection and evaluation of key data. e.g average class size, population demographics, health status of students and staff, ICT facilities available, upcoming examination schedules. Once the data have been collected and analyzed, the school's capabilities in these areas are assessed.
In Step 2 of SWOT analysis, data on the school are collected and sorted into four categories: strengths, weaknesses, opportunities, and threats. Strengths and weaknesses generally comes from factors within the school, whereas opportunities and threats usually arise from external factors. School surveys are an effective means of gathering some of this information, such as data on school's finances, operations, and processes [10].

Step 3 involves the development of a SWOT matrix for each viable alternative under consideration. For example, say a school is evaluating the development of a sport center. They are looking at two options; the first is a wholly owned sport 
center, and the second is a joint venture with other schools. The school's expert panel would complete a separate SWOT matrix for each alternative.

Step 4 involves incorporating the SWOT analysis into the decision-making process to determine which alternative best meets the school's overall strategic plan.

The principal idea here is that SWOT analysis can be applied into Nigeria's secondary school system, while planning. This will help in solving the strategic management issues at this level. SWOT Analysis gives a simple framework for generating alternatives from situation analysis. We seem not to have adapted it in secondary school management in this climes.

The SWOT approach helps identify the school's internal strengths and weaknesses, opportunities and threats of the external environment [35], and consequentially identify the schools unique competencies and key success factors. SWOT's major aims and objectives are to recommend strategies that guarantee the best arrangement between the external and internal environment [47]. When the school head Understands the situation analysis approach, the school can better maximize its strengths, correct its weaknesses, benefits on excellent opportunities, and prevent potentially devastating dangers [32]. The SWOT analysis should be done in a technical meeting to be held with the Strategic Planning Development Team

2. Strategic Formulation If the strategic analysis is completed and the current position of the school system is recognized, the next step is to look at where the school wants to be. It now follows that the mission of the school has been established. It involves setting strategic goals, identifying strategic alternatives as well as evaluating and choosing the strategy that provides the optimum performance of the school in a short, medium and long term. This idea is in line with what (ICMBA, 2004) opined when they emphasized that when a clear picture of an organization and its environment is in mind, specific strategic alternatives can be developed.

3. Strategic Implementation After strategic formulation comes the implementation stage and the bestformulated strategy is unworkable or worthless if it cannot be implemented effectively [47]. If our secondary schools is to achieve the best result for which it was established through its strategic planning efforts, it must make sure that its strategy is put into action [47]. For effective implementation, it needs to be translated into more detailed policies that can be understood at such level. McCune, (1986) reports that the effectiveness of strategic planning in education is based on: "the leadership that backs the plan...the quality of the implementation plan, and the persistence in carrying out the plan"[36]. Also, the effectiveness of strategic planning in education is influenced by the nature of the challenges faced by the schools

4. Strategic Control/Evaluation: This is the final stage of the strategic planning process. It is the performance measure that has to be put in place. Strategic control involves the monitoring of the implementation process thereby ensuring that it is in line with the expected performance. At this stage the key performance indicator will help the school know when its set out goals are met. It defines WHAT success will look like when the goal is achieved, it states HOW the Goals will be addressed: By when, who is accountable to do what for each of the Goals. It is a FOLLOW-UP PROCESS with Regular, timely monitoring of progress on the goals and objectives; includes setting new objectives periodically.

Adeolu, (2018) Stated that all strategies are subject to review and future modification because external and internal factors are constantly changing. Three fundamental strategy evaluation activities are (i) reviewing external and internal factors that are the bases for current strategies, (ii) measuring performance, and (iii) taking corrective actions. These will enable both principals and teachers to make the necessary adjustment in the teaching-learning process in order to achieve the best learning outcome in secondary schools.

Strategic plans must have measurable outcomes that are SMART (specific, measurable, achievable, relevant and timed) [17]

The aim of the schools, as seen by Chaffee, (1990) should be to increase quality and productivity in order to cope with foreseeable socioeconomic problems and to demonstrate behaviors and attitudes so that students can ensure their own future [11]. To do this, educational institutions need to examine and analyze the environment in which they work, their resources, their culture and their stakeholders' expectations. The fundamental purpose of strategic planning is to transition the institution from present status to some desired future and, in the process, to develop a substantial competitive advantage over its competition [26].

Cook (2006) observed that In USA for instance, Strategic planning follows a four step process for planning a school wide program, conducting a comprehensive needs assessment, managing the inquiry process, designing the school wide program, and evaluating the program [14].

Strategic plans can vary in their process, format and content. Strategic plans should include: mission statements, goals, strategies for implementation, and indicators for success [9], [18].

\subsection{The Strategic Planning Process}

1. Who is involved in its development?: School Board; Principals/Administrators; Staff Members; Parents/PTA; Community Members and Students

2. What process was used to develop it? School Board Retreat; Meetings over the year, consultation and collaboration

3 . When was it developed?

4. When was it reviewed/revised? Annually

5. Who has had major responsibility for its design and implementation?: School Principal/or Vice Principal

6. How is the plan used?: As a general guide in school 
planning

7. Under what circumstances or for what issues is the plan normally referred to in making decisions?

i. in budget development

ii. when developing policy

iii. when making decisions

8. How is the Strategic plan Report made available to you: school's website; PTA; NGOs

9. What mechanisms has the division instituted to gather feedback from the community?

website; surveys; community forums/focus groups; data from current students

\section{Strategic Planning for an Educational Setting Is Important for Many Reasons}

Strategic planning is a backbone support to strategic management and it is a major process in the conduct of strategic management. According to Rauch, (2007) the importance of strategic planning can be explained from four points of view including environmental scanning, strategy formulation, and linking goals to budgets and strategic planning as a process.

Strategic plans are considered to be very important in the management and success of organizations. School strategic planning is key to success of a school with regard to achievement of its mission, goals and objectives. Though the Ministry of Education directed that Public Secondary schools must formulate and implement Strategic Plans [20]; some schools have been faced with the challenges of implementation of their strategies.

The plans provide direction in regard to resource targeting and program implementation [20]. One factor that stands out as a key determinant to school success is school planning effectiveness. According to Ndegwah, (2014), strategic planning is a line of action designed by the school to achieve desired targets with a scale using available resources [56].

Since Secondary Schools have many stakeholders who must be involved in the Strategic Planning process. Apart from administrators, the schools board, Parents Teachers Association (PTA), Teachers, staff, and students, the institutions also need to account for the interests of students' parents, government agencies, benefactors, alumni, host community and accreditation agencies. Each of these stakeholders makes demands upon the School and through strategic planning all these stakeholders are brought into the strategic management process to maximize stakeholder's satisfaction.

With many changes in Nigerian educational demographics including the possibility of teacher shortages in some core subject areas, increase student's enrollment, it is particularly important for schools to participate in strategic planning.

Strategic planning is met to achieve the broad goals of improving student outcomes and responding to changing demographics while staying within the funding limits they are given.

According to Bryson, (2011) other benefits of strategic planning include the promotion of strategic thought and action, improved decision making, enhanced organizational responsiveness and improved performance, and direct benefits to an organization's people.

Any school that formulates and implements strategic plan derives benefits such as having negotiated and agreed clear goals and objectives, communication of the set goals to various stake holders, providing a base upon which progress can be measured, building strong and functional teams in management staff who have clear vision on how the school will be in future, providing the school management with new ideas which can steer the school to greater heights of excellence and commits the school funds to a well-organized and coherent development agenda. [47]

According to Finlay, (2000) strategic planning provides significantly better performance than unplanned, opportunistic adaptive approach. It provides an integrative framework for other forms of planning. The planners have to match the activities of the organization to its' environment and also the organizations resource capabilities [22]. Strategic planning has been used in schools in developed countries leading to school improvement.

Wagner, (2006) Suggested five reasons why institutions must develop strategic plans, namely: It is to set direction and priorities; get everyone on the same page; to simplify decision-making; to drive alignment and to communicate the message.

On this note, strategic planning enables people and organization to influence the future.

Mittenthal, (2002) added that, strategic planning is about developing a good match between the activities of an institution and the demands of the environment in which it operates. It focuses on the institution's mission, objectives, strengths, weaknesses, opportunities and threats. In essence, strategic planning aims at ensuring internal efficiency of an organization or institution [38]

Hence, the purpose of strategic planning in a system is basically to ensure that the system is effective in its activities. That is what the Nigerian secondary school system needs now inorder to meet up with the expectations of the national policy on education and properly position itself for the preparation of a well-equipped 21 st century secondary school graduate.

Ololube, Agbor, \& Kpolovie, (2016) in their opinion stated that strategic planning focuses on improving the competitive circumstances and the overall performance of school staff and students.

Therefore, it is safe to say that a school's strategic planning is the process by which it makes decisions and take actions that affects its long-term performance, which is said to be an output of the planning process. It defines both the management and the students in relation to the teaching and learning processes [12].

Bryson, (2011) had outlined eight benefits of strategic planning to any organization viz: solve major organizational 
problems; improve performance;

deal effectively with rapidly changing circumstances; build teamwork and expertise, think strategically; clarify future direction; make today's decisions in light of their future consequences; develop a coherent and defensible basis for decision making; and exercise maximum discretion in the areas under organizational control.

Although the Nigerian educational system has a centralized and long term vision/Policy statement, strategic planning helps to decentralize such and makes it applicable to the class-room teacher and other category of staff in the school.

A strategic plan helps a school define what it intends to achieve when it comes to their student success objectives and organizational goals. A combination of good planning and communication will ensure that all stakeholders including parents, teachers, administrators, principals, board members and community are all striving for the same goals. Successful strategic plan implementation requires proper management of budgetary and time resources, the creation of high-output teams and the consistent monitoring of all progress.

Specifically, that is in direct relation to schools as an organization;

1. A Strategic Plan articulates a shared vision, mission and values

Strategic planning is not for businesses only. Every school that has a mission to succeed must have a plan to get there. This enables all stakeholders to work towards a common vision. I think that a leading cause of employee (Teaching and Non-Teaching Staff) discontent is that employees don't understand how the work they are presently engaged in helps their organization. With a well communicated and executed strategic plan, everyone is informed of their school's goals and how their actions are contributing to the achievement of these goals.

2. A strategic plan effectively organizes schools and their staff

The plan encourages commitment by showing staff members that their work is essential, part of a larger strategy to help their school succeed.

3. A strategic plan defines how success is measured

In order to achieve success, it's important to know what success means. A school with a strategy can monitor its progress toward key outcomes and evaluate where and how it may have gotten off track..

4. A strategic plan aids a school's board with governance decisions and provides direction for the future. With a plan in place, the board has a roadmap which it can track, evaluate and modify to facilitate better governance decisions and provide direction for the future of the school.

5. A strategic plan increases communication and engagement

Communication in schools is critical so that everyone understands his or her responsibilities and departments are effective in coordinating their efforts and keeps everyone connected. As an additional benefit, the plan helps with fundraising, as well. Donors are more likely to support a school that has a clear vision and a strategy to make it happen. A well implemented and communicated plan holds all staff accountable for their actions and encourages collaboration.

6 . The best reason of all for strategic planning comes back to every great school's number one priority: Students

7. Best of all, strategic planning provides a framework so that the most important priority of the school - Students' educational achievement is taken care of.

Needs Assessment in Strategic Planning Process

When preparing to plan it is important to conduct a needs assessment to determine the gaps that exist between what currently is, and what ought to be.

During this process or stage there are some data that would be required; Examples includes: Mission, Vision, Values, or Core Belief Statements; School Profiles, Past Strategic Plans if available; Student Achievement Data and Analyses; Documented Curriculum; Curriculum Audits; Facilities Plans and Audits; Technology Plans and Audits; Life Safety Plans; Budgets and Long-Term Finance Plans; Past Stakeholder Survey Data or Reports; Administrative Organizational Structure Charts and Documents; Past Program Evaluations; Assessment Plan or Assessment Program Documentation; Policy Manuals; Enrollment Projections and Capacity Information; Community Demographic or census Information; Any Other Reports Related to Previous Studies in the school etc.

There are several ways to conduct a needs assessment including direct observation, questionnaires, consultation with persons in key positions, and/or with specific knowledge, review of relevant literature, interviews, focus groups, tests, records and report studies, and work samples [48].

Fogg, (1994) also states that it is not only important to conduct an internal assessment, but an external assessment as well. Fogg added that after strengths, weaknesses, opportunities, and threats (SWOTS) have been identified, priority issues affecting the fundamental ways a business operates and performance is affected can be addressed.

Cook, (2006) states that "Strategic planning is not an event; it is a way of life for any successful organization. That is why periodic updates of the strategic plan are vital not only to the plan but to the organization itself'.

\section{Implementation of Strategic Plans}

Strategic planning generates the strategic plan document when forms the fulcrum for strategic management of the school system. Strategic management is a process that requires collaborative and conscious efforts of top management members in formulating purposeful goals, rational allocation of resources, selecting the best strategies for policies and programmes implementation, job supervision, personal motivation, performance evaluation, policy review and coping with internal and external challenges in order to achieve organizational objectives within the stipulated timeframe. The choice of method for strategic management implementation depends upon situational factors such as size 
of the School, complexity of programs, institutional culture, and the style of the management. In view of the complex characteristics of Secondary Schools, the implementation approach should be based upon high participation.

Education in Nigeria is rapidly changing and technically tailored towards meeting certain goals such as the Education for All [19]

As the second tier of education, secondary education has become the ingredient for the formulation of national policies which when implemented, is expected to enhance growth and development.

Ololube, Agbor, \& Kpolovie, (2016) Suggests that strategic planning is a process. This means that activities are drawn up and systematically analyzed, policies formulation for implementation and control. A strategic plan is described to be effective if the resources put into it are adequate in meeting the specified objectives. An effective strategic plan is one in which the preferred objectives have been achieved [41]. Develop the implementation plan which contains the following: Objectives; Metrics, Actions, Timeline, Responsible Person, and Resources. The implementation plan includes information systems necessary to monitor progress toward the organization's vision and goals.

Strategic plan is a blueprint of action that describes the activities needed for the institution to realize its goals [27]. According to Chukwumah, (2015) at this stage of implementation three key activities are involved; (1) developing short term objectives which are implementable, (2) developing functional tactics, and (3) developing policies that empower action.[15]

The school principals needs to integrate the interrelationship that exists between the internal and external environment of the school to achieve academic competitiveness in teachers' instructional tasks and students' performance. Its the strategic plan that will help the principals appreciate these internal and external environment via SWOT analysis approach while planning.

In developing countries, Jourshari, (2015) stated that the main problem with strategic planning is in the implementation of these strategic plans. Generally, a system must develop plan that ensures that the appropriate products and services are offered to its students and society [26]. To be more precise, strategic planning gives guidance and direction to members of an organization with particular emphasis to their role of products and services delivery [36], it is the process of applying scientific or rational procedures to the process of growth and development to ensure the efficiency and effectiveness of the informative system through strategic planning mechanism [43].

Peterson, (1989) opined that an organization simply cannot know what it is doing and what it intends to do unless it periodically establishes and monitors its goals. Research has shown that strategic planning is one of major steps that schools can take to address the challenges they face in enhancing the quality of their programmes in provision of Education [8].

Since Secondary school sector is the springboard of all educational institutions where students are prepared to take a lasting decision of who they will be in the society tomorrow as they prepare to undertake a university study career. This calls for the need to engage in strategic planning to meet this expectation. Therefore there is need to develop strategy to get to the goals.

Developing a workable strategic plan means dissecting the organization's objectives and strategies and determining which takes precedence. Strategic plan becomes a management tool that serves the purpose of helping an organization to do a better job, because a plan focuses the energy, resources, and time of everyone in the organization in the same direction. According to McNamara, (2016) strategic plan is a tool that provides guidance in fulfilling a mission with maximum efficiency and impact. If it is to be effective and useful, it should articulate specific goals and describe the action steps and resources needed to accomplish them.

\section{Strategic Management Chanllenges in Nigerian Secondary School System}

There are many challenges facing the Nigerian secondary system. These are issues that are plaguing the quality of our young school leavers, affecting their performance in external examination, vocational skill acquisition, level of contribution to national development. Strategic planning and management practices are needed in an environment where new forms of influence are imaging and where norms and values as well as social utility of organizations is being challenged and redefined [7].

This is a brief run-down of some of the strategic planning and management challenges Nigerian secondary school system is facing that would require a strategic approach for closeout.

\subsection{Inadequate Infrastructure, Instructional Materials and Facilities School}

Most Nigerian public secondary school students are exposed to the teaching-learning process under poor infrastructural. Most school lack basic science laboratory, music and art studios, even farm land for agricultural practical-session. Some of the buildings are poorly constructed, chairs and other furniture fittings are not ergonomic. Some instructional materials, which should make it easier for teachers to communicate with learners are either inadequate or not available. All these makes the teachinglearning process unconducive. Which in turn negatively affects the level of lession delivery and students understanding. When it rains in some schools especially in the south, schools are flooded, offcouse the educational objective cannot be fulfilled.

\subsection{Inadequate Motivation/Staff Low Morale Teachers}

Teachers whose morale are low are not likely to perform as expected in the school system.

When there is irregular promotions, low pay package, 
societal perception of the job and many more the morale of teachers are dampened. When teachers are not motivated, their level of job commitment may be low and the objectives of the school may not be accomplished.

It is through strategic planning that the principal can understand the remote needs of his teachers

Non-motivation of teachers affects their performance. This could be in form of paid leave, health services, free lunch, recognition and awards.

\subsection{Poor Education Board and Ministry Monitoring/Supervision of Schools}

Most governments' education parastatals do have monitoring and inspecting teams, but are very weak in monitoring and supervision of schools under their jurisdiction. The primary responsibility of these inspectors is to see that high standards are maintained and that schools are run in accordance with the laid down regulations. They are supposed to visit schools to closely examining the quality of teachers, infrastructural level, and other key areas that need to examine in secondary schools. These inspectors are in two levels-the internal (at school level) and the external (at ministry level). But they rarely discharge their duties. This is an indication of poor implementation of educational sector strategic plans. If this is effectively implemented, secondary schools will reduce the number unqualified teachers, and ensure that students get the best form of quality education that can be.

\subsection{Poor Funding}

The gross under funding of the secondary schools system and the neglect of the maintenance of the physical facilities; Instructional and living conditions have deteriorated in many of these schools; classrooms blocks, libraries and laboratories are nothing to write home about, all leading to decline in academic standards.

Only about $8.44 \%$ of annual budget is reserved for the entire educational sector [39] as against the United Nations Educational Scientific and Cultural Organization (UNESCO) recommended 26 percent of the total budget of a nation. How much will then be for the secondary school sector? This makes it difficult for school mangers to procure imported technical and scientific equipment like books, journals and other instructional needs in the educational system. Nte, (2007) noted that education in Nigeria is in serious financial crisis which threaten its collapse.

This poor funding also affects payment of teachers' salaries, allowances, provision of health care. Once a man's psychological needs are not met their moral will be low. This can affect the proper implementation of the school goals. Teachers being inadequately paid, leads to frequent nationwide teachers' strikes. This affects student's achievement, especially those writing external examinations. Paying the teachers good and adequate salaries will even attract more professional and qualified persons to develop interest in teaching.; and in the long run students will find education rather interesting than stressful. The Educational system in Nigeria today needs strategic planning inorder to reform and improve the performance of secondary school management education in the country. This will involve the designing of suitable guidelines for funding.

\subsection{Unqualified and Inadequate Teachers}

Core subject matter teachers are either inadequate or not available in most public schools especially in the sub-urban and rural areas. This is one of the major challenges with the education sector in Nigeria. The private school owners of most private secondary schools employ unqualified teachers who lack the expertise on teaching profession to teach students.

This demands urgent attention because teachers are the major hub around which the successful implementation of schools goal. The qualified teacher is the fulcrum for strategic implementation of national education plan.

Teachers are the cornerstone or the hub of any educational system. The National Policy on Education states that no education system can rise above the quality of its teachers (NPE, 2004). More so, with rising student population, more teaches needs to be employed. These statistic will come from strategic planning.

\subsection{Poor Application of ICT Computer Learning}

In this $21^{\text {st }}$ century many secondary school teachers do not use computers in lessons presentation. This could be due to factors like electricity problem, non-availability of computer units, no computer lab, or even unqualified teachers or even skill-gap issues. It is no secret that computers are now taking the center stage of learning in the whole world. In some cases where computer-units have been installed, who monitors its use and academic achieve of students using it? Especially now that JAMB exams are CBT-based? There is little or no urgency/concern for the application of ICT in our secondary school system. Many institutions especially the public schools cannot afford to buy or have access to computers and teachers' inability to apply ICT in teaching at secondary school is one of the problems militating against effective implementation of secondary school curriculum.

\subsection{Non-involvement of Stakeholders/Teachers in Key Decision-making and Planning}

Teachers and other key stakeholders needs to be involved in decision-making and planning of school goals and objectives. This helps them take ownership of such ideas and put in all efforts towards implementation of school plans/goals.

Through strategic planning process, all parties would be carried-along and that makes curriculum implementation easy and less stressful.

There are no problems that cannot be surmounted. Through care implementation of the key concept of strategic planning and management these highlighted issues can be strategically handled one at a time. Our apparent lack of 
preparation and plan to cope with the situation have combined to aggravate the problems associated with the process of education in the country.

The comparison between desired and existing situations clarifies the institution's needs related to resources. From these determinations operational programs are developed and implemented [28].

The numerous problems permeating the entire educational system in Nigeria such as non-availability of instructional materials, cultism, examination malpractice, drug abuse, indiscipline, persistent poor academic performance of students in public examinations and many more

\section{Below Is a Model Outline of Strategic Planning Document, Developed from Brainstorming Session Using the SWOT Analysis Approach}

Table 2. A model outline of strategic planning document for schools.

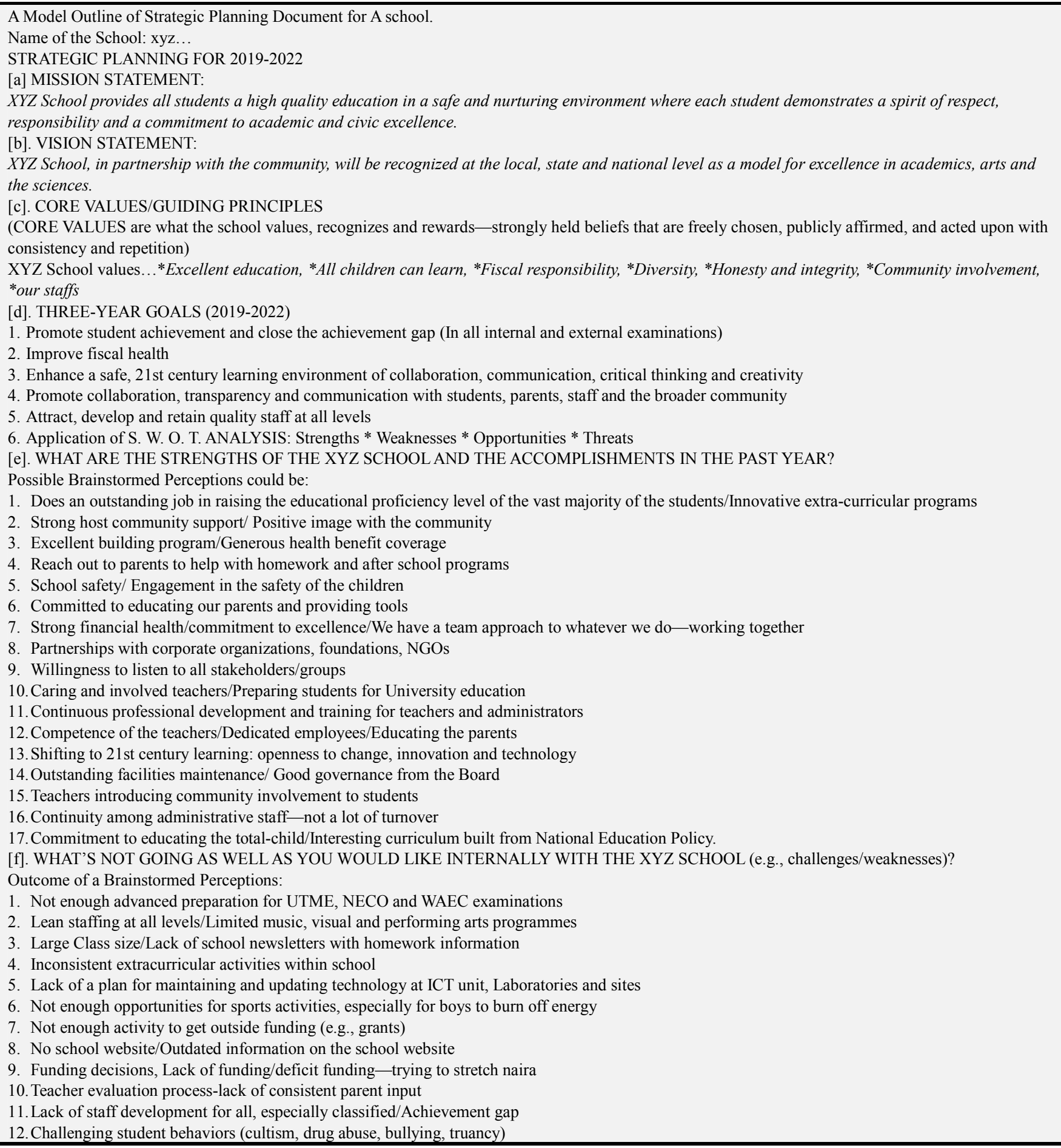




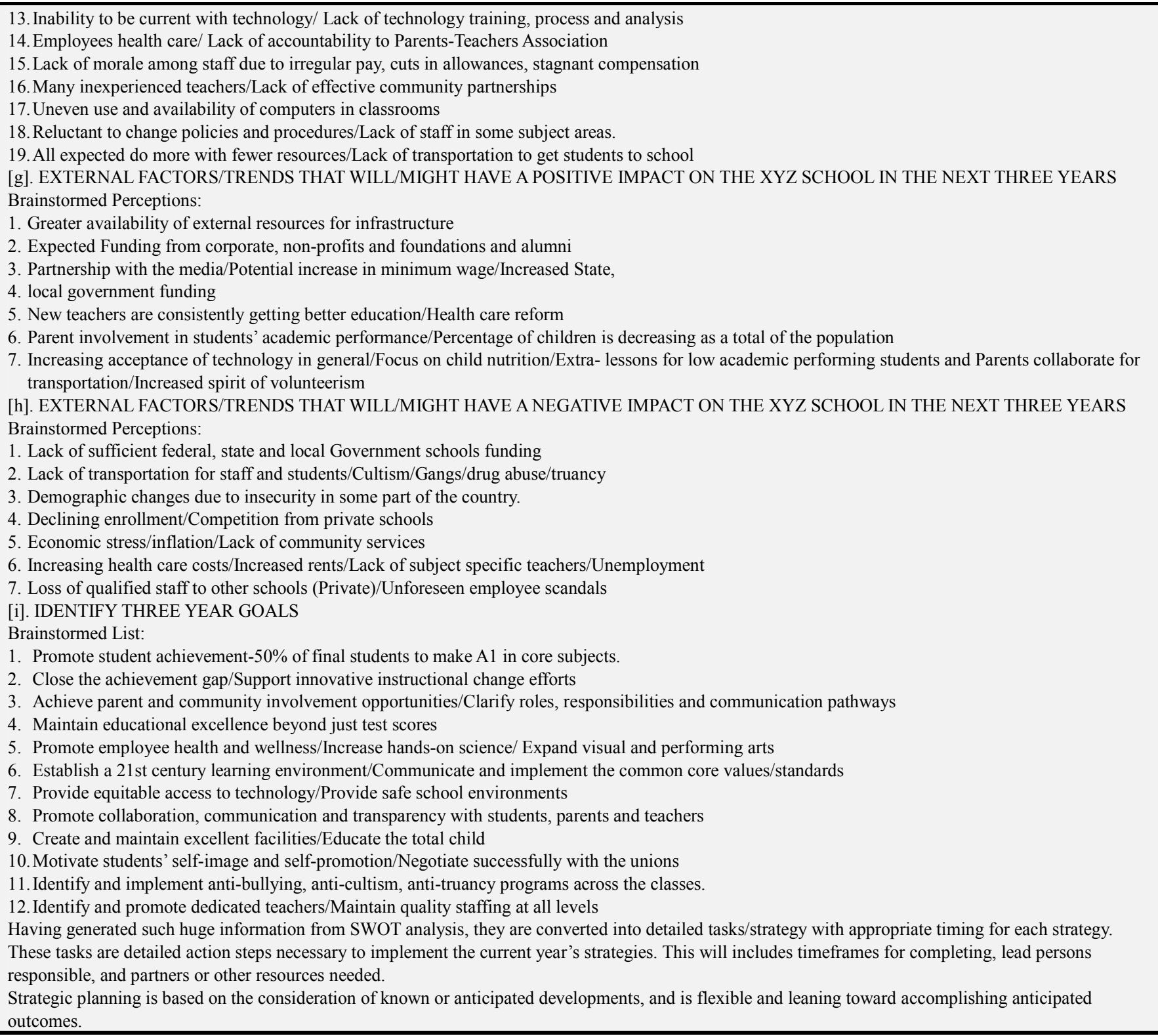

\section{Conclusion}

Finally it is worth mentioning that schools that are operating without strategic plans is an indication of lack of commitment for successful management, which may jeopardize the provision of effective and efficient secondary school-education services, leading to low student achievement.

In this study researcher examined perspectives on strategic planning as a remedy for the successful management of Nigerian secondary school system by reviewing several approaches, including using SWOT analysis to determine the place of organizational strengths, weaknesses, opportunities, threats in secondary school management. This study supports the need to promote research, teaching and learning processes through strategic improvement and management. The internal and external (challenges) Weaknesses facing the
Nigerian secondary system can be strategically improved on diminish their negative impact on the management of the system, While its external opportunities available to the school needs to be expediently grasped to improve the successful management of Nigerian secondary school system.

This research has a lot of conceptual implications for successful management of Nigerian secondary school system. The national policy $\mathrm{n}$ education can only be successfully implemented through strategic planning and management. This review adds to the body of knowledge in the field. As such, this study provides springboard to researchers and practitioners. This study also has implications for secondary school planners, government, administrators, policymakers that are involved in quality successful and effective implementation of the national policy on education, especially the secondary school unit. This ground-breaking investigation is not an end in itself, but rather an important starting point for ongoing research in this domain. In closing, 
the successful inclusion of the schools strengths, weaknesses, opportunities and threats into the strategic planning and management can make important contributions to achieving successful management. Consequently, researchers are encouraged to use the model suggested in this study to further investigate and resolve some of the teething issues of secondary school management.

\section{Solutions/Recommendation}

1. All public and private schools in Nigeria should in line with education ministry requirement formulate strategic plans with a time frame of 3-5 years and action plans for each year.

2. Principals and vice principals should be equipped with the necessary Managerial Skills (Academic and Technical) plus conceptual skills to help them successfully implement strategic plans in their respective schools.

3. Secondary Schools should embrace institutional policies which they should enforce strictly to ensure they help in the successful implementation of the school's strategic plans.

4. Schools should have resources allocation policies / budgets which they should enforce strictly to ensure they help in the successful implementation of the school's strategic plans.

5. Public secondary Schools should have reward / incentive schemes which can help in the successful implementation of the school's strategic plans.

6. Heads of secondary schools in Nigeria should engage host community when developing the school plan.

7. All state government should invest more resources and build the capacity of principals to facilitate proper strategic plans implementation practices in public secondary schools in Nigeria.

\section{Future Research Direction}

1. There should further empirical study of Nigerian secondary schools that has strategic plans

2. More work on Factors that could hinder successful development and implementation of strategic plans and management should carried out.

The model framework in this study can be used to further investigate emerging issues on strategic planning as a remedy for successful management of Nigerian secondary school.

\section{Key Terms}

STRATEGIC PLANNING: is a schools management activity that is used to establish priorities, articulate its energy and resources, improve its area of strength, and guarantee that school staff/teachers and other stakeholders are working toward agreed goals.

STRATEGIC MANAGEMENT: comprises setting objectives, analyzing the school environment, analyzing the internal structure of the organization, evaluating strategies, and ensuring that management employs the planned strategies across the school.

STRATEGIC PLAN: is a developed document used to interact and communicate with the school the institutions goals, the actions-steps required to accomplish those setgoals and all of the other components developed during the planning exercise

SWOT ANALYSIS: is a tool for analyzing the existing situation both internally (strengths and weaknesses) and externally (opportunities and threats). It provides helpful starting position information for a school that desires to vision the future or analyze a problem.

STRATEGY IMPLEMENTATION: Encompasses all those means related to executing the strategic plans

\section{References}

[1] Adeolu A. J. (2018), Principals' Strategic Management and Students' Learning Outcome in Secondary Schools in Ondo State, Nigeria. In: Education Quarterly Reviews, 1 (1), 28-46. ISSN 2621-5799 DOI: 10.31014/aior.1993.01.01.5. The online version of this article can be found at: https://www.asianinstituteofresearch.org/

[2] Ajayi S. A. (2011). The Contemporary Challenges of Education in Nigeria. A Lead paper Presented at the 7 th Annual National Conference of the Association for Encouraging Qualitative Education in Nigeria (ASSEQEN), Held at the Federal College of Education (FCE), Abeokuta, 10th-14th May

[3] Ajobiewe, J. A. (2008 April 21st - 25th). Motivating the Nigerian Secondary School Personnel for Quality Secondary Education. Paper presented at the 51st Annual national Congress of ANCOPSS in Ekiti.

[4] Alexa, A (2011). Five Steps to Strategic Planning. https://www.forbes.com/sites/aileron/2011/10/25/five-steps-toa-strategic-plan/Accessed and Retrieved June 4, 2019

[5] Allison, M., \& Kaye, J. (2005). Strategic planning for nonprofit organizations (2nd ed.). New York: John Wiley.

[6] Anambra State of Nigeria, (2010). Strategic Education Sector Strategic Plan (SESP): 2011-2020 Awka: Anambra State Government \& UNICEF

[7] Ansoff, H. I. \& McDonnell, E. J. (1990). Implanting Strategic Management. (2nd Ed), New York: Prentice Hall.

[8] Bell, L. (2002). Strategic planning and school management: Full of sound and fury, signifying nothing. Journal of Educational Administration, 40 (5), 407-424.

[9] Bryson, J. M. (2011). Strategic planning for public and nonprofit organizations: A guide to strengthening and sustaining organizational achievement (4th ed.). San Francisco, CA: Jossey-Bass Publishers.

[10] Carpenter, S. D. M. (2006). Military leadership in the British civil wars, 1642-1651: the genius of this age. London: Routledge.

[11] Chaffee, E. (1990)"Three models of strategy", Academy of Management Review, 10 (1), 89-98 
[12] Chance, S., \& Williams, B. T. (2015). Assessing university strategic plans: a tool for consideration. Educational Planning, $18(1), 38-54$.

[13] Chang, G. C. (2008). Strategic planning in Education: Some concepts and methods. Paris: UNESCO.

[14] Cook W. J. (2006) Strategic planning in American Schools. (2nd Ed.) Arlington Cambridge group.

[15] Chukwumah, F. O (2015) Developing Quality Strategic Plan In Secondary Schools For Successful School Improvement. Journal of Education and Practice www.iiste.org ISSN 22221735 (Paper) ISSN 2222-288X (Online) 6 (21).

[16] David, F. (2005). The nature of strategic management: Strategic management, concepts and cases. Pearson Education, Inc.

[17] Davis, B. \& Ellison, L. (1998). Strategic planning in schools: an oxymoron? School Leadership and Management, 18 (4), 461-473. Retrieved March 3, 2009 from http://web.ebscohost.com.proxy2.lib.umanitoba.ca/ehost/pdf

[18] Duke. D. L. (1999). Envisioning the good organization: Steps toward a philosophy of organization. In P. Begley (Ed.), Values and educational leadership (pp. 9-24). Albany, NY: State University of New York Press.

[19] Education for All-EFA (2015) National Review: NIGERIA EFA REVIEW REPORT 2000-2014 Strides and Milestones, Federal Ministry of Education, Abuja Publisher.UNESCO

[20] Federal Republic of Nigeria. (2013). National Policy on Education. NERDC Press. Abuja

[21] Federal Ministry of Education (2005). Nigeria Education Sector Diagnosis: A Condensed Version: A Framework for Re- engineering the Education Sector. Retrieved online on September 6th, 2012 from http://www.fme.org

[22] Finlay, P., (2000). Strategy Management. An Introduction to Business and Corporate Strategy. London: Pearson Education Limited

[23] Fehnel, R. (2000). Strategic Planning and the Nigerian University System innovation Project. Report to World Bank on Nigerian University System Innovation Project (NUSIP) September 2000.

[24] Fogg, D. C., (1994) Team-Based Strategic Planning AMACOM

[25] Goodstein L, Nolan T, Pfeiffer J. W. (1993). Applied Strategic Planning. A Comprehensive Guide. McGraw Hill

[26] Hénard, F. (2012). Fostering quality teaching in higher education: policies and practices. Paris: OECD

[27] Hill, C. L. and Jones, G. R. (2013). Strategic Management: An Integrated Approach (10 ed.). Mason, Ohio: Cengage Learning. p. 21. ISBN 9781111825843. Retrieved 2018-06-17.

[28] Hinton, K. E. (2012). A practical guide to strategic planning in higher education. Houston: Society for College and University Planning.

[29] Hu, J., Liu, H., Chen, Y., \& Qin, J. (2017). Strategic planning and the stratification of Chinese higher education institutions. International Journal of Educational Development. doi.org/10.1016/j.ijedudev.2017.03.003

[30] ICMBA (2004). SWOT Analysis. Journal of Internet Center for Management and Business Administration. Retrieved May

\section{0, 2016 from http://www.netmba.com/strategy/swot/}

[31] Ikediugwu NP, Chukwumah FO, 2015. Strategic Plan Implementation and Monitoring in Secondary Schools in Anambra State. Greener Journal of Educational Research, 5 (2): 017-026, http://doi.org/10.15580/GJER.2015.2.012315011.

[32] Jourshari, A. N. (2015). Role of Strategic Management in the Development of Port of Anzali. Journal of Social Issues \& Humanities, 3 (9), 216-222.

[33] Lawrence 1., (2001). Reducing Barriers to Expansion of Schools by Focusing on School Development Plans. Newyork: Emmmerald group publishers.

[34] Marmar M, (2001) Total Quality Management in Education. Turkish Online Journal of Distance Education-TOJDE July 2002 ISSN 1302-6488, 3 (3)

[35] Mason, R. B. (2007). The external environment's effect on management and strategy: A complexity theory approach. Management Decision, 45 (1), 10-28. DOI $10.1108 / 00251740710718935$.

[36] McCune, S. D. (1986). Guide to strategic planning for educators. Alexandria: VA: Association for Supervision and Curriculum Development.

[37] McNamara, C. (2016). All about strategic planning. Retrieved May 31, 2016 from $\mathrm{http} / /$ managementhelp.org/strategicplanning/\#anchor1234.

[38] Mittenthal, R. A. (2002). Ten Keys to Successful Strategic Planning for Nonprofit and Foundation Leaders. Effective Philanthropy: The Importance of Focus. TCC Group, Available at http://www.tccgrp.com and accessed 28/5/2019

[39] Nte, A. R. (2007). Introduction to Educational Planning. PortHarcourt: River State University of Education Press.

[40] Okenwa, G. N. (2013). Extent of community participation in the administration of public secondary schools in Enugu State. Unpublished doctoral thesis. Department of educational foundation, Enugu State University of Science and Technology, Enugu.

[41] Okwako A. D., (2013) Strategic planning and performance of secondary public secondary school in Nairobi county, Published Research project, University of Nairobi

[42] Olaniyonu, S. O. A., Adekoya, S. O. A., \& Gbenu, J. P. (2008) Fundamentals of educational planning (Revised and Enlarged) Lagos: Micodex.

[43] Ololube, N. P. (2006a). Teachers Job Satisfaction and Motivation for School Effectiveness: An Assessment, Essays in Education, 18, 1-19.

[44] Ololube, N. P. (2009a). Understanding teachers professional competencies for education effectiveness. Owerri, Nigeria: Springfield Publishers.

[45] Ololube, N. P. (2013). The problems and approaches to educational planning in Nigeria: a theoretical observation. Mediterranean Journal of Social Sciences, 4 (12), 37-48. DOI: 10.5901/mjss.2013.v4n12p37.

[46] Ololube, N. P., \& Kpolovie, P. J. (2013). Literature and focus group analysis of the approaches and obstacle to effective educational planning in higher education in an emerging economy. International Journal of Scientific Research in Education, 6 (3), 233-254. 
[47] Ololube, N. P., Agbor, C. N., \& Kpolovie, P. J. (2016). Effective communication process: the Responsibility of university management for enhanced organizational justice. In N. P. Ololube (Ed.), Handbook of research on organizational justice and culture in higher education institutions (pp. 34-56) Hershey, PA: Information Science Reference. DOI: 10.4018/978-1-4666-9850-.ch002

[48] Puamau, P. (2006) Principles and processes of educational planning in the Pacific. Journal of Educational Studies, Volume 28 (1 \& 2) 2006

[49] Rouda, H. R. and Kusy. M. E. (1995). Needs Assessment: The First Step. Retrieved on 15th

[50] Rauch, P. (2007). SWOT analyses and SWOT strategy formulation for forest owner in Austria. Eur J Forest Res, 126, $413-420$

[51] Titilayo, H. (2002). Secondary Education in Nigeria: A Boat on a Stormy Sea. Keynote Address delivered to the 45th Annual National Congress of All Nigeria Conference of Principals of Secondary Schools, (ANCOPSS). Abeokuta: ANCOPSS.

[52] Wagner, R. J (2006) Conversation on planning: Investigating the relationship between strategies, actions and performance. Doctoral dissertation, University of Minnesota

[53] Wilkinson, M. (2011). Why You Need a Plan: 5 Good Reasons. Accessed 20/6/2015 from Free Management Library http://managementhelp.org/blogs/strategic-planning

[54] Young, D. (2009) Strategic Planning in Education in Manitoba. A paper prepared for POLS7370 Theory and Practice of Public Administration, University of Manitoba http://citeseerx.ist.psu.edu/viewdoc/versions?doi=10.1.1.602.5 315 Accessed and Retrieved on 5/6/2019

[55] Peterson, D. (1989). Strategic Planning. (ERIC Document Reproduction No. ED 312774)

[56] NDEGWAH, D M (2014) Factors Affecting the Implementation of Strategic Plans in Public Secondary Schools in Nyeri County, Kenya. International Review of Management and Business Research Vol. 3 Issue. 2

[57] https://www.envisio.com/blog/topic/strategic-planning retrieved may 212019

[58] http://educatenigeria.info/5-most-severe-challenges-facingsecondary-school-students/ 